\title{
Serba-serbi Publikasi Riset Indonesia dan Negara ASEAN lainnya
}

\author{
Oleh : RISKI AMALIA MADI
}

Riset atau penelitian menurut $\mathrm{KBBI}$ adalah penyelidikan suatu masalah secara bersistem,kritis dan ilmiah untuk meningkatkan pengetahuan dan pengertian,mendapatkan fakta yang baru, atau melakukan penafsiran yang lebih baik. Melalui riset, berbagai pengetahuan baru bermunculan, rentetan teknologi baru terus dikembangkan. Hasil riset mempunyai peranan yang sangat penting dan strategis dalam menentukan keunggulan kompetitif dan pertumbuhan ekonomi suatu bangsa, sehingga hampir tidak ada negara di dunia ini yang mempunyai daya saing dan pertumbuhan ekonomi tinggi tanpa memberikan perhatian yang serius terhadap riset.

Riset dan publikasi sangat berhubungan erat sebab tanpa publikasi maka sebuah temuan akan menjadi tidak berdampak atau sia-sia. Menurut Dr. Page Morgan, guru besar fisiologi tumbuhan dari Texas A \& M University, menyatakan bahwa hasil penelitian para ilmuwan harus ditulis dan diterbitkan agar punya makna. Hasil penelitian yang tidak menyebar dalam bentuk tulisan tidak akan bermanfaat karena tidak dapat dinilai dan diakui oleh sesama ilmuwan. Namun, Dr. Morgan tidak hanya mengatakan bahwa hasil penelitian harus ditulis, tetapi, yang lebih penting, ditulis dengan baik.

Sedemikian kerasnya "persaingan " dalam dunia sains hingga tidak sembarang penemuan bisa diakui jika tidak dipublikasikan dalam jurnal ilmiah Nasional maupun Internasional. Ada beberapa penemuan atau hasil riset yang agak diragukan keberhasilannya oleh kaum ilmuwan dunia hanya karena alasan yang cukup sederhana, yaitu disebabkan hasil risetnya tersebut tidak dipublikasikan di jurnal ilmiah internasional tetapi mempublikasikan temuannya di surat kabar biasa.

WOS,Scopus, Thomson,DOAJ,GS,OSF,IPI,Portal Garuda,dsb merupakan layanan publikasi/indeksasi jurnal atau karya ilmiah yang berbasis online yang tidak asing lagi buat para dosen atau peneliti. Layanan publikasi ini ada yang open access (gratis) dan ada yang berbayar. Sesuatu yang sangat membuat para peneliti/dosen/author berbangga hati adalah ketika artikel/jurnal/karya tulis tembus atau diterima di salah satu jurnal bereputasi terindeks internasional. Hal ini disebabkan jurnal/karya ilmiah peneliti akan punya kemungkinan lebih besar disitasi dibanding terbit di jurnal biasa misalnya.

Salah satu cara mengukur kinerja para peneliti adalah ketika jurnal/karya ilmiah mereka bisa tembus atau lolos di jurnal yang terindeks nasional bereputasi atau internasional bereputasi. 
Bagaimana kondisi publikasi para peneliti di Indonesia di bandingkan negara ASEAN lainnya? Berdasarkan data SCImago, sepanjang 1996-2016, jumlah publikasi terindeks global Indonesia mencapai 54.146 publikasi. Bila dibandingkan Singapura, Thailand, dan Malaysia, peringkat Indonesia masih jauh berada di bawah ketiga negara ASEAN itu. Pada 2016, di tingkat dunia, Indonesia menempati peringkat 45 untuk jumlah dokumen yang terpublikasi internasional. Di kawasan Asia, posisi Indonesia berada di urutan 11, sementara di tingkat ASEAN peringkat keempat. Selain itu, tren jumlah dokumen publikasi di Singapura, Thailand, Malaysia, dan Indonesia terus meningkat. Mulai 2010, Malaysia menggeser posisi Singapura ke peringkat kedua. Terkait dokumen yang terpublikasi di Indonesia, jumlahnya meningkat menjadi 46,41 persen (11.470 publikasi) jika dibandingkan 7.834 publikasi pada 2015. Kendati naik, angka ini masih jauh bila dibandingkan Singapura (19.992 publikasi) dan Malaysia (28.546 publikasi). (https://tirto.id)

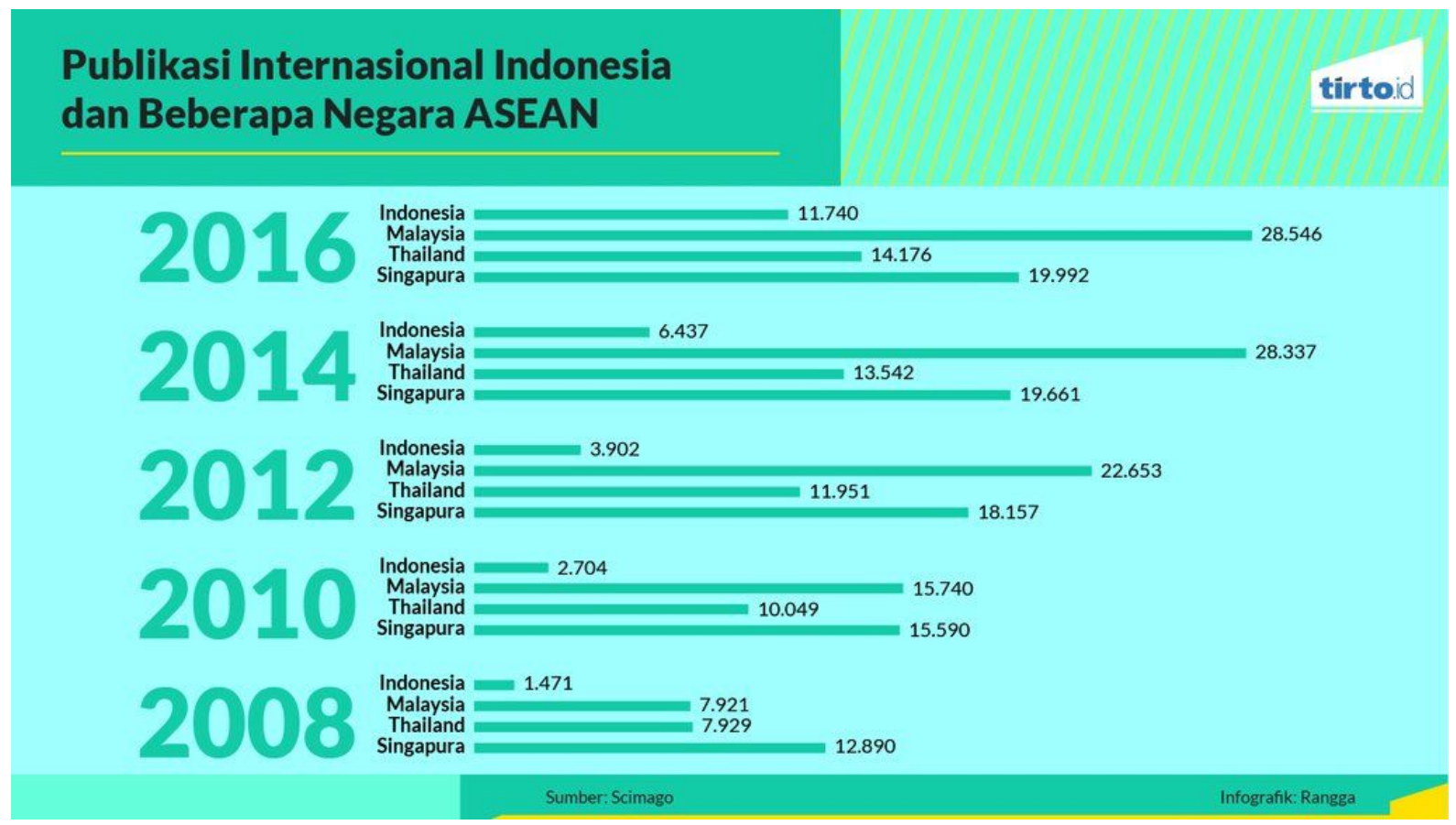

Sumber: SCImago

Menariknya, jumlah citation atau kutipan mengalami tren penurunan sejak 2013. Selain itu, meski Malaysia berada di peringkat pertama dalam jumlah dokumen yang terpublikasi, tetapi bila dilihat dari jumlah citation, Malaysia berada di peringkat kedua (19.024 kutipan) setelah Singapura (32.504 kutipan) pada 2016. Thailand berada di peringkat ketiga (11.331 kutipan) dan Indonesia keempat (4.604 kutipan).

Rendahnya jumlah karya tulis yang terpublikasi secara internasional dapat disebabkan oleh beberapa hal,yaitu: 
1. Sedikitnya jumlah peneliti di Indonesia. Data Lembaga IImu Pengetahuan Indonesia (LIPI) pada 2017 menunjukkan peneliti di Indonesia (hanya) berjumlah 9.685 orang. Angka tersebut merupakan jumlah peneliti di seluruh pejabat fungsional peneliti dari seluruh Kementerian/LPNK di Indonesia.

Memang ada tren kenaikan kuantitas sejak 2010. Pada 2010 jumlah peneliti di Indonesia mencapai 7.502 orang, pada 2012 berjumlah 8.075 orang. Angka terus meningkat menjadi 9.128 orang pada 2014. Meski jumlahnya terus bertambah, jumlah ini masih terbilang sedikit dibandingkan negara di kawasan ASEAN. Sebab, rasio jumlah peneliti dengan jumlah penduduk di Indonesia adalah 90 peneliti berbanding 1 juta penduduk.

2. Minimnya anggaran riset. Negara-negara dengan perekonomian maju memiliki komitmen tinggi untuk berinvestasi dalam riset. Mereka percaya riset berperan dalam mendorong pertumbuhan ekonomi. Bentuk komitmen ini dilihat dari rasio pengeluaran penelitian dan pengembangan terhadap PDB -atau Gross Expenditure on R\&D (GERD). Di tingkat ASEAN, yang memiliki rata-rata GERD per PDB tinggi adalah Singapura (2,0 persen) dan Malaysia (1,1 persen). Sementara itu, GERD per PDB Indonesia belum mencapai angka 1 persen -hanya sebesar 0,085 persen- dan jauh tertinggal dibandingkan GERD dunia.

3. Kemampuan dosen Indonesia untuk membuat jurnal memang masih kurang, apalagi untuk yang berbahasa Inggris. Padahal, jurnal dalam bahasa Inggris merupakan salah satu kunci agar penelitian mereka diakui secara internasional. Selain keterampilan menulis lemah, publikasi ilmiah yang dilakukan oleh peneliti juga masih kurang. "Dalam setahun penelitian yang dipublikasikan di Indonesia maksimal hanya sekali, padahal jika melihat negara-negara lain, seperti Tiongkok publikasi ilmiah bisa mencapai tiga hingga empat kali dalam setahun," Perguruan tinggi diharapkan bisa memberikan pendampingan terhadap dosen yang melakukan penelitian, terutama bagi dosen pemula agar penelitian yang dihasilkan bisa digunakan bagi masyarakat luas, baik itu berupa produk atau sistem statistik.

4. Peranan sektor swasta atau bisnis/industri belum menunjukan proposri yang signifikan. Diperlukan dorongan agar proporsi sektor swasta atau bisnis dalam penelitian dan pengembangan dapat meningkat. Penghargaan terhadap hasil riset tidak hanya mengandalkan dana APBN, tetapi dibutuhkan peran serta sektor swasta. Di Cina, Malaysia, maupun beberapa negara lain, mewajibkan sektor swasta menyediakan anggaran tertentu untuk penguatan penelitian.

Paparan data di atas menunjukkan dunia riset Indonesia masih harus banyak dibenahi. Bukan hanya pemerintah, tetapi juga keterlibatan sektor swasta. Peningkatan anggaran menjadi hal penting untuk meningkatkan jumlah penelitian dan publikasi ilmiah. Selain itu, belum nyambungnya hasil riset dengan kebutuhan 
industri juga menjadi persoalan yang memerlukan solusi.

Hal lain adalah pentingnya pengelolaan dan pemanfaatan sumber daya riset yang belum optimal, seperti anggaran, fasilitas riset, serta kuantitas dan kualitas para peneliti. Semua hal ini perlu dibarengi dengan meningkatkan budaya dan literasi ilmu pengetahuan dan teknologi bangsa Indonesia. 